\title{
Evaluating the Application of Public-Private Partnership (PPP) Funding Models in Public Nursing Institutions in Hubei Province, China
}

\author{
Peiqi Deng*
}

\author{
${ }^{1}$ Hubei Academy of Social Sciences, Wuhan, China \\ *Corresponding author. peiqideng@163.com
}

\begin{abstract}
A rapid ageing population is raising the demand for elder care and brought about profound effect to social policy in China. So, nowadays, many researchers begin to study this problem. Financing is one of the important ways to solve this problem. This paper tries to find a suitable way of capital intervention in pension, and conducts three case studies in three nursing institutions in Hubei: Wuchang District Sunshine Welfare House, Hanchuan Social Welfare House, and Wuhan Social Welfare House, which are operated under three Public-Private Partnership (PPP) funding models respectively. After investigation and analysis, we find that after PPP reform, the scale of these nursing institutions is extended, accommodation rates and service quality improve greatly, and more jobs are created. However, there are still some problems need to be considered, such as loss of public features, heavy financial burden, and unexpected distortions.
\end{abstract}

Keywords: Ageing, China, Elder care funding, Public-and-Private Partnership (PPP)

\section{INTRODUCTION}

Before 2000, government was the dominant funder and provider of Chinese elder care. However, from the late 1990s, new social policy was under discussion to transform the state's role in this field. Since 2000, Chinese government started to explore more diversified forms of investment and the involvement of different market providers under a program of 'Socialisation of Social Welfare'. The private companies and non-profit organisations (NGOs) are encouraged to fund elder care. New financial initiatives, such as, preferential tax treatment and subsidy support (via welfare lottery funds), were also introduced to attract more social participants to develop elder care. Since 2014, Chinese government promoted Public-Private Partnership (PPP) model to introduce marked-based management and operation in the public nursing institution. Such measures emphasized how policy reduces the government's role and increases financial resources by integrating other public and market- dominated agencies into the provision and funding of elder care. In the last few decades, PPP has emerged as quasi-market organisational and system form of governance regime. It refers to a cooperative combination of resources between state and private sector (businesses or NPOs) to deliver public goods and services for social purposes ${ }^{[1-3]}$. PPP arrangements cover the design, financing, construction, and operation of public utilities. The major purported advantages of PPP are briefly summarised as follows: (1) Through adopting advanced expertise and technology from the private partner, PPP can increase the efficiency of delivery of qualified products and services in order to meet the clients' demands. (2) It can reduce the fiscal risk and guarantee adequate public expenditure by using private capital. (3) Such capital allocation allows governments and private companies to co-operate through contracting and the purchase of services. Thus, PPP promises to minimize state and market failure by providing quality public products and services at low cost. In the field of elder care/long-term care (LTC), many studies focus on LTC financing by combining private LTC insurance with public insurance scheme ${ }^{[4-8]}$. Some research focuses on the delivery and management of LTC and discussion on the opportunities and challenges of PPP approaches. In addition, other research focuses on the overall situation of the PPP reform through reviewing and analysing LTC policy ${ }^{[9-10]}$.

While there are many theoretical models to justify this co-operation between market and the state, assessments of actual performance and outcomes in PPP reform of public nursing institution are scant. This paper will fill this void by assessing three different PPP models 
proposed by Chinese government - 'Private Construction and Public Subsidy', 'Public Construction and Private Operation' and PPP elder care project, which have been launched in three public nursing institutions respectively in Hubei Province, China. Each has involved a different public-private co-ordination of funding and administrative structure. The objective is to analyse and evaluate the performances achieved by a range of partnership systems which will contribute to future policy discussions on viability of models of collective provision, specifically how different types of financing mechanisms contribute to the construction and development of elder care in China.

\section{INVESTIGATION}

This part discusses and analyses how each PPP model performs, based on three nursing institution in Hubei Province, with specific reference to the funding of these nursing institutions under various modality of coordinated co-operation among public and private firms.

Model 1: 'Private Construction and Public Subsidy' model (the case of SWH)

\section{(1) Financing plan}

By investigating some practitioners, $\mathrm{SWH}$ is a private non-profit organisation, unlike the public sector, it is very hard for SWH to apply bank loans. During developing financing plan, nearly all sources of funding approximately 4.8 million RMB must be self-financing. A one-off subsidy from local government is $2000 \mathrm{RMB}$ per bed. The other one-off subsidy from local government is $100 \mathrm{RMB}$ per person/month and doubled from 2017 until now. So, the institution received a total fiscal financial supplement of 6.72 million RMB.

(2) The actual operating conditions

After investigation, the major operating costs are rent, approximately 1.2 million RMB. The annual operating income of the organization is about 2 million RMB which are mainly from medical care. In additional, there are nearly 300 employees in SWH. Considering the maintenance costs and staff salaries, there is a funding gap that needs to be replenished.

At present, nearly all the beds are rented out. One third of them are used for medical care, two third of them are used for non-medical elder care. The fee of medical care is divided into six levels: $1600,1400,1200,1000,800,600 \mathrm{RMB}$ per person/month. The rent fee of one bed is larger than $400 \mathrm{RMB}$ and less than $1000 \mathrm{RMB}$ per person/month. So, the total monthly fee for each elderly person is nearly $2400 \mathrm{RMB}$.

Model 2: 'Public Construction and Private Operation' (the case of HSWH)
During an investigation in May 2015, more than 50\% of the beds were founded to be empty most of the time. In interview, the president of HSWH stated that several problems mar the delivery of public elder care as below:

Firstly, the subsidy of 'Three-Nos' elderly people in Hanchuan is much lower than the standard of Minimum Living Standard Support (MLSS) system of Hubei Province. So, it's hard for elderly people to pay for beds in nursing homes.

Secondly, the nursing institution has strict requirements for the elderly people. For example, the elderly people with infectious diseases, mental disorders, and even chronic diseases are not allowed to live. Because take care of special population will exacerbate the running cost. Although this is not the result of financial pressures (e.g., recruiting professional nurses), the institution also bears the risk of accidental death of the elderly.

Thirdly, the administrative staff in HSWH are civil servants, so their salaries are determined by the governments. They cannot benefit from extra care. So, they did not like receiving private customers.

All the above survey contents explain the low accommodation rate of HSWH.

Model 3: PPP elder care project (the case of WSWH)

WSWH was built in 1964 which covers an area of 2000 square meters and contains more than 800 beds. The whole institution is divided into two parts_-Block A and Block B. Block A is a public agency which is running by WSWH, and continues its original functions and responsibilities. Block $\mathrm{B}$ is running by two private companies which named Jiuzhoutong Pharmaceutical Group Limited Company (Jiuzhoutong) and Shanghai Renshou National Pharmaceutical Limited Company (Renshoutang). The funding sources of block B are mainly depended on PPP modes.

The PPP project on the Block B is depend on a ROT(Rebuild-Operate-Transfer) model, and its contract lasts for 25 years. WSWH united the other two private companies and formed a Special Purpose Company (SPC) - Wuhan Jiuzhoutong Renshoutang Medical and Elder Care Limited Company. This firm is mainly undertaking the operation of Block B.

The total investment of PPP project for the reform of WSWH is nearly 124 million RMB. The capital was shared by WSWH and those two private firms. In detail, WSWH, and two private companies invested 2.48 and 223.2 million RMB respectively (10\% and $90 \%$ of the registered capital). The funding is used for improving medical facilities and employing more professional nursing staff. Therefore, the service level of Block B is much better than Block A. And the occupancy rate is also very high. 


\section{DISCUSSION AND EVALUATION}

Reviewing three typical cases of PPP projects on elder care in Hubei Province, funding initiatives in these nursing institutions have offered rich lessons for the rest of China, as they involve different strengths and limitations from which others can learn when determining their own PPP funding options. This section discusses and evaluates each model described above.

Model 1: 'Private Construction and Public Subsidy' model

Firstly, as to the perspective of its funding structure, the government investment only accounts for $20 \%$ of the maintenance funds. It is very hard for the non-profit institution to maintain operations in the absence of funds. So, when the SWH are mainly relying on self-financing for the pre-period construction, the effect of reform will be very limited.

Secondly, SWH completely operates under a marketoriented and privatized system. This allows the organization to determine prices and sell services to those who can afford them. As SWH can determine its own pricing structure and enjoy more subsides than private nursing institution, for the purpose of attracting more people to live, their service and bed fees should be set lower. However, lower pricing will lead to lower operating income.

Thirdly, although cheaper price will attract more elderly people to live, the quality of service will also decrease. So, this model seems to benefit suppliers rather than customers.

Model 2: 'Public Construction and Private Operation' model After reform, HSWH find the balance point between government financing burden and improving pension services (accommodation rate increased from below $40 \%$ to more than $70 \%$ ). The reform combines the advantages of market mechanism and government funding. On the one hand, this model can use market-oriented funds to improve service level. On the other hand, the government's funding can be used to make up for the shortcomings of the facilities. However, this mode also has its disadvantages:

Firstly, the government subsidies are depended on the level of regional economic development. In Hanchuan, the subsidies are very low which may not support the environmental transformation.

Secondly, the pricing of institutional services is not only related to the integrity of institutional facilities, but also to the market demand. The consumption ability of people in underdeveloped areas is poor, and it is often difficult to bear high costs. In Hanchuan, many elderly people's annual income is less than $1000 \mathrm{RMB}$. So, they may not be able to afford the elder care.
Thirdly, government subsidies are also affected by the local economy. In the implementation process of the model, the government funds are afforded by a private company. So, this strategy creates a heavy economic burden for the private investor which will force them to increase the service fees in the future.

Model 3: PPP elder care project

In a PPP elder care project, Jiuzhoutong and Renshoutang can make full use of the advantages of being private companies. The business can not only provide over 1000 jobs, but also has improved the provision of medical/elder care within the local communities. Besides, the long-term contract between private company and public sector encourages companies to sustainable develop this project.

Moreover, this PPP elder care project is very successful in dealing with financial pressure. Not only the Block B in WSWH is supported by the private enterprise, the Block A in WSWH build by public sector can also be benefit. For example, many high-grade medical facilities can be shared by two regions.

However, this PPP elder care project has three limitations that needs to be highlighted.

Firstly, the negotiation period for the contract is quite long (e.g., 20 40 years), so the transaction cost is high. The president stated at an interview that the two private companies paid over 1 million RMB when tendering to secure the contract, as well as 1 million RMB annually to a separate accounting firm. So, the development of PPP elder care project is slow and it is difficult to meet the demand for elder care in the long term.

Secondly, as the private nursing institution operates solely on market basis and pursues a high profit strategy, so they fix a comparatively high price for care service. In Hubei Province, the average pension amount for most elderly people is around 2,000 3,000 RMB/month (Ministry of Human Resources and Society Security, 2019), so most of them are unable to afford these high fees if they do not have extra income.

Thirdly, public nursing institutions still contain substantial bureaucracies. Like the second case, the public nursing institution (Block A) also refuses to accept private elderly people. No matter how many elderly people are in residence, the staff working at the public nursing institution still receive a fixed income, so without any additional incentive, they would rather keep the empty beds than offer them to the private clients. In addition, interviews revealed that the private companies pay 6.16 million to the public nursing institution annually. Instead of inputting this money to the construction and operation of public nursing institution, all this money is issued to the administrative staff to enhance their additional welfare. 


\section{CONCLUSION}

To sum up, the three cases examined in this paper represent meaningful policy experiments of attempts to re-orientate social policy away from redistribution and towards market principle, in the search for a suitable elder care funding model. Although the sheer size of China frustrates any attempt of a one-size-fits-all funding model, several implications for PPP funding for elder care can be drawn. First, the public nursing institutions need to conduct reforms from the following four aspects such as the market entities, the public nursing institutions, the government, and the private elderly people. Second, more subsidies should be invested in the operational stage of private nursing institutions, in order to reduce the price and increase service staff income. Third, excessive investment in the construction of PPP elder care projects is not appropriate, rather social policy should consider funding models which can stimulate elderly people's purchasing power.

\section{REFERENCES}

[1] T. Bovaird, 2006. Developing New Forms of Partnership with the 'Market' in the Procurement of Public Services, Public Administration 84(1): 81102.

[2] C. Skelcher, 2007. Public-Private Partnerships and Hybridity, in Ferlie, E., Laurence E. Lynn Jr., and Pollitt, C. (eds). The Oxford Handbook of Public Management, Oxford: Oxford University Press, pp. 347-370.

[3] C. Greve and G. Hodge, 2010. Public-Private Partnerships and Public Governance Challenges, in Osborne, S. P. (ed.). The New Public Governance: Emerging Perspectives on the Theory and Practice of Public Governance. London: Routledge, pp. 149162.

[4] M. R. Meiners and H. L. Mckay, 1989. Developing Public-Private Long Term Care Insurance Partnerships. Pride Institute Journal of Long Term Home Health Care 8(4):35-40.

[5] G. Arling, S. Hagan, and H.B. Dring, 1992. The Feasibility of a Public-Private Long-Term Care Financing Plan. Medical Care 30(8): 699-717.

[6] K. J. Mahoney and T. Wetle, 1992. Public-Private Partnerships: The Connecticut Model for Financing Long-Term Care. Journal of the American Geriatrics 40(10): 1026-1030.

[7] H. I. Doerpinghaus and S. G. Gustavson, 2002. LongTerm Care Insurance Purchase Patterns. Risk Management and Insurance Review 5(1): 31-43.
[8] D. G. Stevenson, M. A. Cohen, E. J. Tell, and B. Burwell, 2010. The Complementarity of Public and Private Long-Term Care Coverage. Health Affairs 29(1): 96-101.

[9] E.A. Miller, V. Mor and M. Clark, 2010. Weighing Public and Private Options for Reforming LongTerm Care Financing: Findings from a National Survey of Specialists. Medical Care Research and Review 67(4): 16-37.

[10] B.L. Bihan, C. Martin, 2010. Reforming Long-term Care Policy in France: Private-Public Complementarities. Social Policy \& Administration 44(4): 392-410. 